Background: Familial cold autoinflammatory syndrome 3 (FCAS3) is an autoinflammatory disease (AID) caused by mutation of the PLCG2 gene, which has not been reported in China. We will report 2 cases of Chinese FCAS3 patients with no claimed family history, but we found the same mutations in a parent during their genetic analysis. After further inquiry of the parent's medical history, we confirmed that actually, they were two FCAS3 families. Through a literature review, we found that the clinical features of Chinese patients are milder than foreign countries, and their symptoms are concealed and may be ignored, resulting in mistakes in family history collecting. Objectives: To summarize the genetic and clinical features of Chinese FCAS3 patients and to provide diagnostic recommendations for the disease.

Methods: Two suspected AID children with recurrent fever and urticaria were enrolled in this study. Clinical data and family history were collected, and genetic analysis was performed by next-generation sequencing (PID panel or WES) and Sanger-based validation. Literature was reviewed from PubMed, CNKI, and Wanfang Database.

Results: The two children were both diagnosed to be FCAS3 with PLCG2 mutation. The clinical manifestations of 2 children were recurrent fever, urticaria, and increased ESR and CRP. Case 1 has a paternal, and Case 2 has a maternal heterozygous mutation in the PLCG2 gene, while both had claimed without a family history. Further inquiry showed the two parents used to have a fever with urticaria. By comparing with foreign literature, we found our patients were milder than abroad patients. Large fragment deletions were relatively more common in foreign patients.

Conclusion: We reported the case of FCAS3 in China for the first time. Their genotype and phenotype were different from foreign patients. Their symptoms are mild, and heterozygous mutations are more common than foreign patients, which are the main differences. The difference in mutation type may be the reason for different clinical manifestations. Besides, both two families showed a trend of more severe clinical features in the next generation. As the symptoms of the elders were not obvious and may be ignored, it caused trouble for the genetic diagnosis. Therefore, family history should be collected carefully. For rashes and fevers, which are not too severe in overall symptoms, care should be taken about the possibility of AIDs. Genetic testing can help to make a definite diagnosis.

References:

[1] Pathak S, Mcdermott M F, Savic S. Autoinflammatory diseases: update on classification diagnosis and management[J]. Journal of Clinical Pathology, 2017, 70(1):1-8

[2] Broderick, L., Hereditary Autoinflammatory Disorders: Recognition and Treatment. Immunol Allergy Clin North Am, 2019. 39(1):13-29.

[3] Milner, Joshua D. PLAID: A Syndrome of Complex Patterns of Disease and Unique Phenotypes[J]. Journal of Clinical Immunology, 2015, 35(6):527-530.

4] Picard C, Gaspar H B, Al-Herz W, et al. International Union of Immunological Societies: 2017 Primary Immunodeficiency Diseases Committee Report on Inborn Errors of Immunity[J]. Journal of Clinical Immunology, 2017, 38(SuppI 1):96-128.

[5] Ombrello M J, Remmers E F, Sun G, et al. Cold Urticaria, Immunodeficiency, and Autoimmunity Related to PLCG2 Deletions[J]. New England Journal of Medicine, 2012, 366(4):330-8.

[6] Zhou Q, Lee GS, Brady J, et al. A Hypermorphic Missense Mutation in PLCG2, Encoding Phospholipase Cy2, Causes a Dominantly Inherited Autoinflammatory Disease with Immunodeficiency[J]. American Journal of Human Genetics, 2012, 91(4)

[7] Neves, J.F., et al., Novel PLCG2 Mutation in a Patient with APLAID and Cutis Laxa. Front Immunol, 2018. 9: 2863.

[8] Mcdermott M F, Aksentijevich I, Galon J, et al. Germline mutations in the extracellular domains of the $55 \mathrm{kDa}$ TNF receptor, TNFR1, define a family of dominantly inherited autoinflammatory syndromes[J]. Cell, 1999, 97(1):133-144.

Disclosure of Interests: None declared

DOI: 10.1136/annrheumdis-2020-eular.862

\section{AB1068 REGULATORY EFFECT OF SHORT-TERM LOW DOSE OF IL-2 RESTORES REGULATORY T CELLS IN IGG4- RELATED DISEASE}

Y. Wu ${ }^{1}$, X. C. Zhao ${ }^{2}$, J. Luo ${ }^{2} .{ }^{1}$ Shanxi Medical University, Taiyuan, Shanxi, China, Taiyuan, China; ${ }^{2}$ Department of Rheumatology, the Second Hospital of Shanxi Medical University, Taiyuan, China, Taiyuan, China

Background: Little known about the roles of peripheral immune cell subsets in IgG4-related disease (IgG4-RD)

Objectives: The aim of our study was to analyze the role of low-dose interleukin-2 (Id-IL2) on these cells in IgG4-RD.

Methods: The percentage and absolute counts of lymphocyte subpopulations [CD3+ (T cells), CD4+, CD8+, CD19+ (B cells) and CD16+CD56+ (NK cells)] and CD4+T cell subsets (Th1, Th2, Th17, regulatory $T$ (Treg)) using single platform flow cytometry in 25 IgG4-RD patients which were admitted and treated, as well as 24 healthy controls (HCs). Among IgG4-RD patients, 19 patients given only conventional treatments while 5 patients were were not only given conventional treatments but also received Id-IL2 ( 0.5 million IU/day) for 5 days.

Results: We found that the absolute counts of T, CD4+T and Th1 cells were increased in the peripheral immune cells of IgG4-RD patients when compared with HCs. Meanwhile, the percentage of B, Th2, Th17 and Treg cells demonstrated significantly decreased. The ratio of Th1/Th2 and Th1/Treg in IgG4-RD patients were higher than that in HCs. After IL-2 administration, the absolute numbers of Treg cells increased dramatically, furthermore, the proportion of Treg cells had a trend towards higher values compared with those before treatment. Conversely, the ratio of Th2/Treg was downward. There were no any significant differences in the above subsets between before and after conventional treatments.

Conclusion: Our findings support that the reduction of Treg cells in IgG4-RD patients, as well as Id-IL2 combined with conventional treatments were able to restore the Treg cells.

\section{References:}

[1] Akiyama M, Sasaki T, Kaneko Y, et al. Serum soluble interleukin-2 receptor is a useful biomarker for disease activity but not for differential diagnosis in IgG4-related disease and primary Sjögren's syndrome adults from a defined population. Clin Exp Rheumatol, 2018.

[2] Zhang SX, Wang J, Sun $\mathrm{HH}$ et al. Circulating regulatory $\mathrm{T}$ cells were absolutely decreased in dermatomyositis/polymyositis patients and restored by low-dose IL-2. Ann Rheum Dis, 2019

Disclosure of Interests: None declared

DOI: 10.1136/annrheumdis-2020-eular.3649

\section{AB1069 CONSIDERATION OF YAO SYNDROME AS A DIFFERENTIAL DIAGNOSIS FOR HEREDITARY PERIODIC FEVER SYNDROMES}

Q. Yao'. ' ${ }^{1}$ Stony Brook University, Rheumatology, Stony Brook, United States of America

Background: Yao syndrome (YAOS, OMIM 617321), formerly termed nucleotide-binding oligomerization domain 2(NOD2)-associated autoinflammatory disease, is characterized by periodic fever, dermatitis, arthritis, and swelling of the distal extremities, as well as gastrointestinal and sicca-like symptoms. This disorder shares similar clinical phenotypes with hereditary periodic fever syndromes (HPFS) and thus can mimic one another.

Objectives: This study aimed to exemplify by a comparison of YAOS vs familial Mediterranean fever (FMF)

Methods: In this retrospective study, electronic medical records of a series of patients with YAOS were analyzed. All patients underwent genetic testing for periodic fever syndrome 6-gene panel (MEFV, TNFRSF1A, NLRP3, MVK NLRP12 and NOD2).

Results: All patients were Caucasian and had recurrent fever, patchy erythema arthralgia, and gastrointestinal symptoms (Table 1). With negative DNA sequencing for MEFV, these patients were treated with colchicine for presumed FMF with a good response in patient 2 and minimal or transient response in other two patients. Further genetic testing identified the NOD2 variants. Unlike HPFS, YAOS is generally sporadic and is mostly reported in adults; spongiotic dermatitis is common; YAOS is associated with the NOD2 variants, IVS +158 in nearly all patients, IVS $8+158 / R 702 W$ in up to $30 \%$, and IVS $8+158 / 1007$ fs, G908R or other rarer NOD2 variants in some patients.

Conclusion: YAOS can masquerade HPFS like FMF. Molecular analysis should cover NOD2 whole gene sequencing to help distinguish these diseases.

\section{References:}

[1] Yao Q, et al. Dermatitis as a characteristic phenotype of a new autoinflammatory disease associated with NOD2 mutations. J Am Acad Dermatol. 2013;68(4):624-31.

Trueb B, et al. Coincidence of NOD2-Associated Autoinflammatory Disease (Yao Syndrome) and HCV Infection With Fatal Consequences: Interaction Between Genes and Environment. J Clin Rheumatol. 2018 Dec 28. doi: 10.1097/RHU.0000000000000963. [Epub ahead of print] China

[2] Yao Q. Research letter: Effectiveness of canakinumab for the treatment of Yao syndrome patients. J Am Acad Dermatol. 2019.

[3] Yao Q, Shen M, McDonald C, Lacbawan F, Moran R, Shen B. NOD2-associated autoinflammatory disease: a large cohort study. Rheumatology (Oxford). 2015;54(10):1904-12.

[4] Yao Q, Shen B. A Systematic Analysis of Treatment and Outcomes of NOD2-Associated Autoinflammatory Disease. Am J Med. 2017;130(3):365 e13- e18.

[5] McDonald C, et al. Alterations in nucleotide-binding oligomerization domain-2 expression, pathway activation, and cytokine production in Yao syndrome. Autoimmunity. 2018;51(2):53-61. 
Table 1. Demographic and Clinical Data of Patients

\begin{tabular}{|c|c|c|c|c|}
\hline Patient & Demographics & Phenotype & Laboratory & $\begin{array}{l}\text { Prior Diagnosis(Dx) and } \\
\text { Treatment }\end{array}$ \\
\hline 1 & $\begin{array}{l}\text { Age Onset: } 63 \\
\text { Age at YAOS Dx: } 66 \\
\text { Gender: } F \\
\text { Caucasian: Yes }\end{array}$ & $\begin{array}{l}\text { Fever: High grade, lasting up to } 36 \text { hrs } \\
\text { Skin: Patchy erythema on face, lasting up to } 2 \text { wks } \\
\text { Arthritis: Knee and ankle } \\
\text { Gl: Abd pain, non-bloody diarrhea. Gl workup: negative for IBD } \\
\text { Sicca: Yes } \\
\text { Asthma: Yes } \\
\text { Family history: No }\end{array}$ & $\begin{array}{l}\text { ESR)/CRP: Normal } \\
\text { MEFV: Neg } \\
\text { 6-gene panel: positive for NOD2 } \\
\quad \text { IVS8+158, R702W, heterozygous }\end{array}$ & $\begin{array}{l}\text { FMF: Yes } \\
\text { Colchicine(col): Transient } \\
\quad \text { response }\end{array}$ \\
\hline 2 & $\begin{array}{l}\text { Age Onset: } 7 \\
\text { Age at YAOS Dx: } 49 \\
\text { Gender: } F \\
\text { Caucasian: Yes }\end{array}$ & $\begin{array}{l}\text { Fever: High grade } \\
\text { Skin: Patchy erythema on face, chest, abd, limbs, lasting up to } \\
6 \text { wks } \\
\text { Arthritis: Knee, ankle and toe } \\
\text { Gl: Abd pain, nonbloody diarrhea, lasting up to } 4 \text { d. GI workup: } \\
\text { neg for IBD } \\
\text { Sicca: Yes } \\
\text { Asthma: Yes } \\
\text { Family history: Yes }\end{array}$ & $\begin{array}{l}\text { ESR/CRP: Normal } \\
\text { MEFV: Neg } \\
\text { 6-gene panel: positive for NOD2 } \\
\text { IVS8+158, heterozygous }\end{array}$ & $\begin{array}{l}\text { FMF: Yes } \\
\text { Col: Good response }\end{array}$ \\
\hline 3 & $\begin{array}{l}\text { Age Onset: } 15 \\
\text { Age at YAOS Dx: } 35 \\
\text { Gender: F } \\
\text { Caucasian: Yes }\end{array}$ & $\begin{array}{l}\text { Fever: Low grade } \\
\text { Skin: Patchy erythema on arms and legs, lasting a few d } \\
\text { Arthritis: Knee and shoulder } \\
\text { GI: Abd pain with nausea and vomiting, lasting a few hrs. GI } \\
\quad \text { workup: neg for IBD } \\
\text { Sicca: No } \\
\text { Asthma: No } \\
\text { Family history: No }\end{array}$ & $\begin{array}{l}\text { ESR/CRP: Normal } \\
\text { MEFV: Neg } \\
\text { 6-gene panel: positive for NOD2 } \\
\quad \text { IVS8+158, 1007fs, heterozygous }\end{array}$ & $\begin{array}{l}\text { FMF: Yes } \\
\text { Col: Minimal response }\end{array}$ \\
\hline
\end{tabular}

Acknowledgments: The author is thankful to the statistician, Ms. Erin Taub for her help with making the table.

Disclosure of Interests: None declared

DOI: 10.1136/annrheumdis-2020-eular.1449

\section{AB1070 DIVERSITY ANALYSIS OF INTESTINAL FLORA IN PATIENTS WITH BEHCET'S DISEASE}

X. F. Yin ${ }^{1}$, Z. Mingxing ${ }^{1}{ }^{1}$ The Second Hospital of Shanxi Medical University, Taiyuan, China

Background: Behçet's disease (BD) may be regarded as a polygenic autoinflammatory disease although adaptive immune system has also been implicated in pathogenesis. The specific components of the microbiota with BD that affect the host response leading to disease remain unknown. Regulation of intestinal microbiota would be able to provide new strategy and target for the treatment of BD. Objectives: To study the diversity and the intestinal flora of intestinal microbes in patients with $\mathrm{BD}$ and further provide new ideas for clinical treatment.

Methods: The stool specimens of $13 \mathrm{BD}$ patients were analyzed at the level of the Phylum, family and genus, and compared with that of 50 healthy controls $(\mathrm{HC})$.

Results: Compared with controls, the abundance of intestinal microbiota in patients with BD was significantly different.At the level of phylum, the abundance of Firmicutes was significantly reduced in BD patients compared with that of $\mathrm{HC}(\mathrm{P}<0.05)$ (fig. 1).At the genus level, in the BD group, the abundance of Klebsiella is significantly increased $(\mathrm{P}<0.05)$, but the abundance of Clostridium IV, Lachnospiracea incertae sedis, Anaerostipes and Megasphaera were significantly lower than that of healthy controls. $(\mathrm{P}<0.05)($ fig. 2$)$

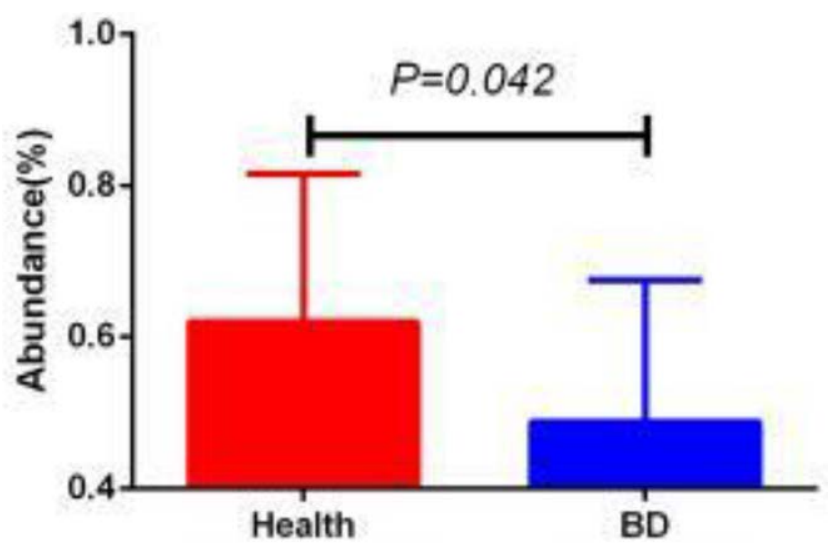

\section{Firmicutes}

Figure 1. the differences between patients with $\mathrm{BD}$ and normal healthy adults were compared at the level of the phylum

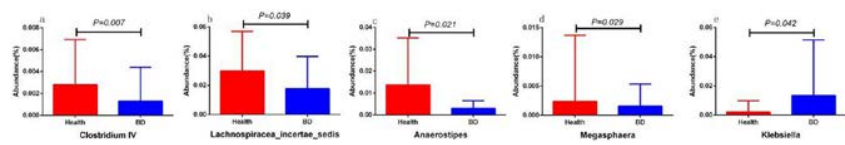

Figure 2. the differences between patients with $\mathrm{BD}$ and normal healthy adults were compared at the level of the genus

Conclusion: The diversity and balance of bacterial community in intestinal microecological environment of patients with $\mathrm{BD}$ are significantly different from the healthy control. Intestinal microbiota disorder may be related to the pathogenesis of $\mathrm{BD}$, which might provide theoretical foundation for the regulation of intestinal flora for disease intervention.

Disclosure of Interests: None declared

DOI: 10.1136/annrheumdis-2020-eular.5832

\begin{tabular}{|l|l}
\hline AB1071 & COEXISTENCE OF FAMILIAL MEDITERRANEAN \\
& FEVER WITH SPONDYLOARTHRITIS: CLINICAL \\
& CHARACTERISTIC AND TREATMENT OUTCOMES
\end{tabular}

T. Yüce İnel ${ }^{1}$, I. Sari ${ }^{1}$, M. Birlik ${ }^{1}$, G. Can ${ }^{1}$, F. Onen ${ }^{1} .{ }^{1}$ Dokuz Eylul University Faculty of Medicine, Izmir, Turkey

Background: Studies indicate that there is an association with spondyloar thritis ( $\mathrm{SpA}$ ) and familial mediterranean fever (FMF) based on the following: 1) increased incidence of sacroiliitis in FMF, 2) MEFV gene mutations are significantly increased in ankylosing spondylitis (AS) and 3) both SpA and FMF show some common clinical manifestations such as the pattern of arthritis. However, characteristics of SpA associated with FMF such as clinical characteristics and treatment outcomes have been poorly documented and additional data is required on this topic.

Objectives: To study the clinical and treatment characteristics of patients associated with FMF and SpA.

Methods: Twenty-eight patients with FMF and SpA who were registered in our database were included in the study. Demographic, clinical, and laboratory data were collected. HLA-B27, MEFV gene mutations were recorded. Pelvic radiographs and sacroiliac joint magnetic resonance imaging (MRI) (if present) were scored based on the modified New York criteria (mNYc) and ASAS MRI definitions respectively. Treatment data were also recorded.

Results: There were 28 FMF-SpA patients in the study (mean age $45.1 \pm 16.4$ years, $57.2 \%$ male). The mean age of onset of FMF and SpA were $31.9 \pm 17.9$ and $35.5 \pm 16.2$ years respectively. SpA patients were predominantly axial $(n=21,75 \%)$, and only 7 (25\%) were mainly peripheral type. Fifteen (53.5\%) patients were satisfying $\mathrm{mNYc}$ for AS. Four (14\%) patients were fulfilling ASAS non radiographic axial $\mathrm{SpA}$ definition. Bone marrow edema was detected in $(36 \%)$ of the patients who underwent MRI $(n=14)$. Two $(7.1 \%)$ patients had SpA symptoms but did not classify into any of the ASAS arms. Arthritis observed in $19(67.8 \%)$ patients with mostly in oligoarthritis type $(79 \%)$. Ankle and knees were the most affected joints. Total hip replacement was present in $7 \%$ of the patients. Amyloidosis confirmed by biopsy was detected in $4(14 \%)$ 